\title{
Identification of $\alpha$-enolase as a nuclear DNA-binding protein in the zona fasciculata but not the zona reticularis of the human adrenal cortex
}

\author{
Weiye Wang*, Lishan Wang*, Akira Endoh ${ }^{1}$, Geoffrey Hummelke, \\ Christina L Hawks and Peter J Hornsby \\ Department of Physiology and Sam and Ann Barshop Center for Longevity and Aging Studies, University of Texas Health Science Center, San Antonio, \\ Texas, USA \\ ${ }^{1}$ Maternal-Fetal Neonatal Care Center, Hamamatsu University School of Medicine, Hamamatsu, Japan \\ (Requests for offprints should be addressed to P J Hornsby, University of Texas Health Science Center, 15355 Lambda Drive STCBM 3.100, San Antonio, \\ TX 78245, USA; Email: hornsby@uthscsa.edu) \\ *(W Wang and L Wang contributed equally to this work)
}

\begin{abstract}
In order to establish whether there are differences in DNA-binding proteins between zona fasciculata (ZF) and zona reticularis $(Z R)$ cells of the human adrenal cortex, we prepared nuclear extracts from separated ZF and ZR cells. The formation of DNA-protein complexes was studied using an element in the first intron of the type I and type II $3 \beta$-hydroxysteroid dehydrogenase genes (HSD3B1 and HSD3B2). Using the element in the HSD3B2 gene as a probe, a complex (C1) was formed with extracts from $\mathrm{ZF}$ cells but was formed only at a low level with ZR cell extracts. Another pair of complexes (C2/C3) was formed with both ZF and ZR cell extracts. The ZF-specific protein forming $\mathrm{C} 1$ was enriched by column chromatography on DEAE-Sepharose and carboxymethylSepharose. Oligonucleotide competition analysis on the enriched fraction gave results consistent with those ob-
\end{abstract}

tained on the unfractionated material. A further enrichment was brought about by passing the protein over an oligonucleotide affinity column based on the HSD3B2 element. The protein bound to the column was identified as $\alpha$-enolase by mass spectrometry. Although $\alpha$-enolase is a glycolytic enzyme, it binds to specific DNA sequences and has been found to be present in nuclei of various cell types. We performed immunohistochemistry on sections of adult human adrenal cortex and found $\alpha$-enolase to be located in nuclei of ZF cells but to be predominantly cytoplasmic in ZR cells. Transfection of an $\alpha$-enolase expression vector into NCI-H295R human adrenocortical cells increased HSD3B2 promoter activity, suggesting a possible functional role for this protein in regulation of HSD3B2 expression.

Journal of Endocrinology (2005) 184, 85-94

\section{Introduction}

In the human adrenal cortex the zona reticularis (ZR) is biochemically and functionally distinct from the zona fasciculata (ZF; Hornsby 1995). The most significant difference is the level of $3 \beta$-hydroxysteroid dehydrogenase ( $3 \beta-H S D)$ activity. The type II enzyme, the product of the HSD3B2 gene, is expressed in steroidogenic tissues, whereas the type I enzyme, the product of the HSD3B1 gene, is expressed in non-steroidogenic tissues (Lachance et al. 1991). HSD3B2 mRNA is present at high levels in $\mathrm{ZF}$ cells but is almost absent from ZR cells (Endoh et al. 1996). This difference is likely the key factor in causing ZR cells to secrete dehydroepiandrosterone and its sulfate (DHEAS) rather than cortisol (Hornsby 1995). In previous experiments we demonstrated differences in cortisol/ DHEAS production ratios and HSD3B2 mRNA in ZR and ZF cells isolated by microdissection (Endoh et al. 1996). Immunocytochemical data also show striking zonal differences in 3 3 -HSD protein levels (Sasano et al. 1990, Parker 1997, Gell et al. 1998). There are a variety of other differences between ZF and ZR cells. DHEA sulfotransferase is expressed at a higher level in ZR cells (Kennerson et al. 1983, Parker 1997). MHC class II gene expression also differs between the zones (Marx et al. 1997). A survey of differences in gene expression between $\mathrm{ZF}$ and $\mathrm{ZR}$ cells revealed several other differentially expressed genes (Wang et al. 2001). The molecular basis for functional differences between ZF and ZR cells remains unknown, but recent data implicate the transcription factor GATA-6 (Jimenez et al. 2003). Moreover functional features of ZR cells can be produced by treating an adrenocortical cell line with Src tyrosine kinase inhibitors (Sirianni et al. 2003). 
In the present experiments we sought to elucidate other differences between ZR and ZF cells, specifically differences in nuclear DNA-binding proteins. In beginning this work we took advantage of experiments previously performed by Guerin et al. (1995) on the HSD3B1 gene, showing that an element in the first intron of the gene binds a $37 \mathrm{kDa}$ protein. These authors showed that the first intron is important in transcriptional regulation, and they pointed out that this element differs in sequence between HSD3B1 and HSD3B2, although the two genes are otherwise very similar in sequence. We show that this element in HSD3B2 binds nuclear proteins; some of these are also bound by the element from HSD3B1, but some are bound only by the element from HSD3B2. One protein is present in nuclear extracts from $\mathrm{ZF}$ cells but is present only at low levels in ZR cell nuclear extracts. We identified this protein as $\alpha$-enolase, a multifunctional protein already established as a DNA-binding protein and transcriptional regulator (Feo et al. 2000, Subramanian and Miller 2000).

\section{Materials and Methods}

Preparation of nuclear proteins from human and bovine adrenal glands

Adrenal glands were obtained from kidney organ donors or from patients undergoing resection of the kidney for renal neoplasms. Using microdissection, the ZR was separated from the $\mathrm{ZF}$ on the basis of color (brown for $\mathrm{ZR}$ and bright yellow for ZF; Endoh et al. 1996). Glands were trimmed free of fat and placed in culture medium. Under the dissecting microscope glands were sliced, the boundary between the ZR and ZF was identified, and fragments of zonal tissue were excised by inspection of color. Tissue fragments were dissociated to cell suspensions using enzymatic and mechanical dispersal $(3 \mathrm{~h}$ incubation with $1 \mathrm{mg} / \mathrm{ml}$ type I collagenase and $0.1 \mathrm{mg} / \mathrm{ml}$ DNase, both from Sigma Chemical Co; Hornsby and McAllister 1991). Larger fragments and debris were removed by filtration. Cells were washed by low-speed centrifugation, once in serum-containing medium, and then three times in PBS.

The preparation of nuclear extracts was based on a procedure published previously (Wang and Klein 1996). Cell pellets (about $0.3 \mathrm{ml}$ by volume) were resuspended in $600 \mu \mathrm{l} 10 \mathrm{mM}$ Tris-HCl, pH 7.6, $1.5 \mathrm{mM} \mathrm{MgCl}_{2}$, $10 \mathrm{mM} \mathrm{KCl}$ and $0.5 \mathrm{mM}$ dithiothreitol (DTT). After 15 min incubation on ice, cells were homogenized by passing them through a 23-gauge needle and the sample was centrifuged for $5 \mathrm{~min}$ at $12000 \mathrm{~g}$. The nuclear pellet was resuspended and salt extracted in $100 \mu \mathrm{l} 20 \mathrm{mM}$ Tris- $\mathrm{HCl}, \mathrm{pH} 7 \cdot 6,25 \%$ sucrose, $0.42 \mathrm{M} \mathrm{NaCl}, 1.5 \mathrm{mM}$ $\mathrm{MgCl}_{2}, 0.2 \mathrm{mM}$ EDTA and $0.5 \mathrm{mM} \mathrm{DTT}$, and was
HSD1

HSD1a

HSD1b

HSD1c

HSD1d

GßI-A
GGACACAGAATGTTTGCAAAAAAAATGGGGTGGAGGAAAA
GGTCATGGAATTTTGCATAAAAAATGGGGTGGAGGAAAA
GGTCATGGAATTTTGCATAAAAAATGG
GGACACAGAATGTTTGAAAAAAAATGG
GGACACAGAATTTTGCATAAAAAATGG

HSD2

HSD2a

$\mathrm{HSD} 2 \mathrm{~b}$

HSD2C

HSD2d

GGTCATGGAATTTTTGTAAAAAATGGGGTGGAGGAAAA GGACACAGAATGTTTGAAAAAAATGGGGTGGAGGAAAA GGACACAGAATGTTTGAAAAAAATGG GGTCATGGAATTTTTGTAAAAAATGG GGTCATGGAATGTTTGAAAAAAATGG

Figure 1 Sequences of oligonucleotides used in these experiments. The region of the first intron of HSD3B1 previously characterized by Guerin et al. (1995) is shown, together with the sub-elements within this region termed $3 \beta \mathrm{I}-\mathrm{A}$ and GT box by these authors. The $3 \beta \mathrm{I}-\mathrm{A}$ sequence was shown to bind a $37 \mathrm{kDa}$ protein (Guerin et al. 1995). The upper set of oligonucleotides is based on HSD3B1 and the lower set is based on HSD3B2. The oligonucleotides designated 1 and 2 are the unmodified sequences. The other oligonucleotides have been modified from these by truncation at the $3^{\prime}$ end and/or by mutation of the indicated nucleotides.

incubated on ice for $30 \mathrm{~min}$. After centrifugation at $15000 \mathrm{~g}$ for $10 \mathrm{~min}$, the supernatant (nuclear protein) was removed for storage at $-80{ }^{\circ} \mathrm{C}$.

\section{Gel-mobility shift assays}

Gel-mobility shift assays were performed as previously described (Wang and Klein 1996). Double-stranded DNA oligonucleotides were prepared by annealing and were then purified by electrophoresis on 15\% acrylamide gel. Oligonucleotides were $5^{\prime}$ end-labeled with $\left[\gamma_{-}{ }^{32} \mathrm{P}\right]$ ATP and T4 polynucleotide kinase. Usually $2 \mu \mathrm{g}$ nuclear protein and $2 \times 10^{4}$ c.p.m. probe $(2-5 \mathrm{fmol})$ were used in each binding reaction. A volume of 10-20 $\mu \mathrm{l}$ buffer comprising $20 \mathrm{mM}$ Tris- $\mathrm{HCl}$, pH 7·6, $100 \mathrm{mM} \mathrm{KCl,} 5 \mathrm{mM} \mathrm{MgCl}$, $1 \mathrm{mM}$ DTT, $10 \%$ glycerol and $2 \mu \mathrm{g}$ poly $(\mathrm{dI}-\mathrm{dC})$ was used. After $30 \mathrm{~min}$ at room temperature complexes were separated by non-denaturing gel electrophoresis on $5 \%$ polyacrylamide. Complexes were visualized by autoradiography.

Probe sequences for the HSD3B1 and HSD3B2 genes are shown in Fig. 1. The c-myc P2 promoter oligonucleo-

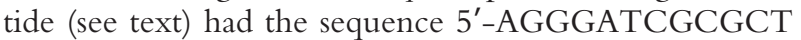
GAGTATAAAAGCCGGTTTTCGGGG-3' (Ray and Miller 1991).

\section{Chromatography on DEAE and carboxymethyl columns}

Protein fractionation by DEAE ion-exchange chromatography was based on published procedures for other DNA-binding proteins (Thomas et al. 1995, An et al. 1996, Vostrov and Quitschke 1997). A $200 \mu$ l DEAESepharose column (Amersham Pharmacia Biotech) was 
prepared in a $1 \mathrm{ml}$ syringe and equilibrated with binding buffer containing $40 \mathrm{mM} \mathrm{KCl}$. Nuclear extract was applied to the column. Proteins were eluted in the same buffer. Fractions were assayed by gel-mobility shift assay as described above. Carboxymethyl-Sepharose chromatography was performed in the same way.

\section{Purification of protein on oligonucleotide affinity column}

The starting material for protein purification was $1.5 \mathrm{mg}$ nuclear extract protein (IMR32; Santa Cruz Biotechnology, Santa Cruz, CA, USA). The protein was first passed through DEAE- and carboxymethyl-Sepharose columns as described above. The eluate was then further purified on an oligonucleotide affinity column. The column was prepared as follows: a double-stranded oligonucleotide was prepared in which the $5^{\prime}$ end of the top strand of the HSD3B2 element (sequence 2 in Fig. 1) was linked to the $3^{\prime}$ end of the bottom strand with a short hairpin. The hairpin had an amino-modified base which was used to bind the oligonucleotide to the column. The complete oligonucleotide was synthesized from three constituent oligonucleotides, comprising (part 1 , hairpin) $5^{\prime}$ pAATTCCATGACCTTXTTGGTCAT- ${ }^{\prime}$, where $\mathrm{X}$ is amino- $\mathrm{C}_{6}$-deoxyuridine, (part 2, top strand) $5^{\prime}$ pGGAATTTTTGTAAAAAATGGGGTGGAAGGAA AA-3' and (part 3, bottom strand) 5'-TTTTCCTCC ACCCCATTTTTTTACAA-3'. To construct the hairpin $20 \mathrm{nmol}$ part 1 and part 2 were annealed, and then the product was incubated with part 3 together with 30000 units T4 DNA ligase in a reaction volume of $30 \mu \mathrm{l}$ at $37^{\circ} \mathrm{C}$ for $18 \mathrm{~h}$. The ligated double-stranded oligonucleotide was then isolated by non-denaturing PAGE. The appropriate band was visualized by ethidium bromide staining, eluted in Tris buffer and precipitated with $\mathrm{LiCl} /$ ethanol.

The purified double-stranded oligonucleotide was conjugated to DSB-X biotin succinimidyl ester (comprising desthiobiotin linked to succinimidyl ester by a seven-atom aminohexanoyl X spacer; Molecular Probes, Eugene, OR, USA). Eight nmoles purified double-stranded oligonucleotide was reacted with $200 \mu \mathrm{g}$ DSB-X biotin succinimidyl ester in $0 \cdot 1 \mathrm{M}$ sodium tetraborate, $\mathrm{pH} 8 \cdot 5$, at $23^{\circ} \mathrm{C}$ for $6 \mathrm{~h}$. The product (conjugate of double-stranded oligonucleotide with DSB-X biotin) was precipitated with $\mathrm{LiCl} /$ ethanol. It was redissolved in Tris buffer $(20 \mathrm{mM}$ Tris, $100 \mathrm{mM} \mathrm{KCl}, 5 \mathrm{mM} \mathrm{MgCl}, 1 \mathrm{mM}$ DTT and $100 \mu \mathrm{g} / \mathrm{ml}$ poly(dI-dC), $\mathrm{pH} 7 \cdot 6$ ) and added to a column of streptavidin-agarose beads (Molecular Probes), equivalent to $20 \mathrm{nmol}$ streptavidin $(0.3 \mathrm{ml})$. The column was washed with $20 \mathrm{ml}$ of the same buffer.

The material from the DEAE and carboxymethyl columns (approximately $30 \mathrm{ml}$ ) was added to the oligonucleotide affinity column. The column was then washed with $10 \mathrm{ml}$ of the same buffer. The oligonucleotide with attached protein was eluted from the beads by incubation with shaking with $100 \mathrm{mM}$ biotin in $80 \mathrm{mM}$ Tris and $2 \mathrm{mM}$ sodium bicarbonate, $\mathrm{pH} 6 \cdot 5$, for $20 \mathrm{~min}$. The protein was captured on a PVDF membrane by passing the eluate through the membrane, and the membrane was then washed with buffer and dried. The dried protein on PVDF was subjected to analysis by mass spectrometry (nano-liquid chromatography electrospray ionization tandem MS). This analysis was performed by Proteome Factory AG (Berlin, Germany). Database matching of identified peptide sequences was performed using the Mascot program (Matrix Science, London, UK).

\section{Immunohistochemistry}

Portions of human adrenal glands were fixed in $4 \%$ paraformaldehyde and were dehydrated and embedded in paraffin using standard techniques. Sections $(4 \mu \mathrm{m})$ were deparaffinized and rehydrated using graded alcohol concentrations. Antigen retrieval was performed by incubation in $100 \mathrm{mM}$ sodium citrate, $\mathrm{pH} 6 \cdot 0$, and were subjected to three cycles of heating in a microwave oven for $3 \mathrm{~min}$ followed by $10 \mathrm{~min}$ of cooling. After nonspecific binding was blocked with 10\% horse serum (10 min), sections were incubated with a rabbit antihuman $\alpha$-enolase antibody (product 6880-0410; Biogenesis, Kingston, NH, USA) at a 1:100 dilution for $40 \mathrm{~min}$ at room temperature. Bound primary antibody was visualized by incubation of sections with a secondary antibody (biotinylated goat anti-rabbit; Vector Laboratories, Burlingame, CA, USA) at a 1:100 dilution for $1 \mathrm{~h}$. The sections were washed in buffer and then a quantum dot conjugate (Qdot 655 streptavidin conjugate; Quantum Dot Corp., Hayward, CA, USA) was added at $10 \mathrm{nM}$ in the manufacturer's buffer for $5 \mathrm{~min}$ followed by washing. The sections were counterstained with $4^{\prime}, 6^{\prime}$-diamidino-2phenylindole (DAPI) at $10 \mathrm{ng} / \mathrm{ml}$ and photographed using fluorescence microscopy.

\section{Promoter activity assay}

The $-1019 /+202$ and $-1019 /+13$ regions of the human HSD3B2 gene were generated by PCR. For the PCR reaction, the $5^{\prime}$ and $3^{\prime}$ primers contained, respectively, KpnI and XhoI sites at their $5^{\prime}$ ends. The PCR products were subcloned into the pGL3-Basic luciferase reporter plasmid (Promega). An expression vector for human $\alpha$-enolase, in which the full-length $\alpha$-enolase cDNA is expressed from a cytomegalovirus promoter, was obtained from Invitrogen.

NCI-H295R human adrenocortical cells were cultured in 24-well plates at a density of $(1-5) \times 10^{5}$ cells/well in medium with $2.5 \% \mathrm{Nu}$-Serum (BD Biosciences, Franklin Lakes, NJ, USA) for $24 \mathrm{~h}$ before transfection. Cells were transfected with Lipofectamine 2000 (Invitrogen) using the manufacturer's protocol. Luciferase reporter constructs and the $\alpha$-enolase expression plasmid were co-transfected 
with the internal control vector pRL-TK (encoding Renilla luciferase; Promega). Total DNA transfected per well $(2 \mu \mathrm{g})$ was kept constant by adjusting the amount of empty pGL3-Basic vector. $48 \mathrm{~h}$ after transfection, cells were harvested and the cell lysates were assayed for luciferase activities with the dual-luciferase reporter assay system (Promega). Firefly luciferase activities were normalized to Renilla luciferase activity.

A one-way ANOVA was used to compare the influence of $\alpha$-enolase on reporter activity, accepting $P<0.05$ as significant. Statistical analyses were performed using the StatView 5.0 program (Abacus Concepts, Berkeley, CA, USA).

\section{Results}

In these experiments we took advantage of the previous characterization of an element in the first intron in HSD3B1 (Guerin et al. 1995). The sequences of this region in HSD3B1 and HSD3B2 are shown in Fig. 1. The sequences differ by the presence of two bases (CA) found in HSD3B1 but not in HSD3B2 and by base differences at five other positions, as indicated in the figure. This element in HSD3B1 was shown to bind a $37 \mathrm{kDa}$ protein in gel-mobility shift assays, producing a complex designated R1 (Guerin et al. 1995). The R1 complex was formed by extracts from a variety of established cell lines, both steroidogenic and non-steroidogenic, but human adrenocortical tissue was not investigated. Here, we investigated the formation of the R1 complex using nuclear extracts from human adrenocortical tissue, separated into ZF and ZR cells (Fig. 2). The R1 complex was observed using extracts from both zones, as well as with HeLa cell nuclear extract. Moreover, the R1 complex was not disrupted by the presence of an excess of an oligonucleotide based on HSD3B2, indicating that the R1 protein does not bind to this element in HSD3B2.

Guerin et al. (1995) noted several less-prominent DNA-protein complexes when using an element from HSD3B1 as probe, which required higher protein concentrations for visualization (Guerin et al. 1995). We observed that the other complexes formed by the element from HSD3B1 were disrupted in the presence of an oligonucleotide based on HSD3B2. Therefore, in the following experiments, we investigated proteins binding to the HSD3B2 sequence. Several complexes were formed by the element from HSD3B2 using extracts from ZF and ZR cells (Fig. 3). In four separated ZF/ZR-cell preparation pairs, ZF cell extracts consistently formed a complex (designated C1) that was present at a much lower level in ZR cell extracts, whereas other larger complexes were formed in all extracts. A complex of similar size to the C1 complex was also formed from bovine adrenal cortex nuclear extract. When the same cell extracts were used with a control oligonucleotide (Sp1), no differences in complex formation was noted between samples (Fig. 3).

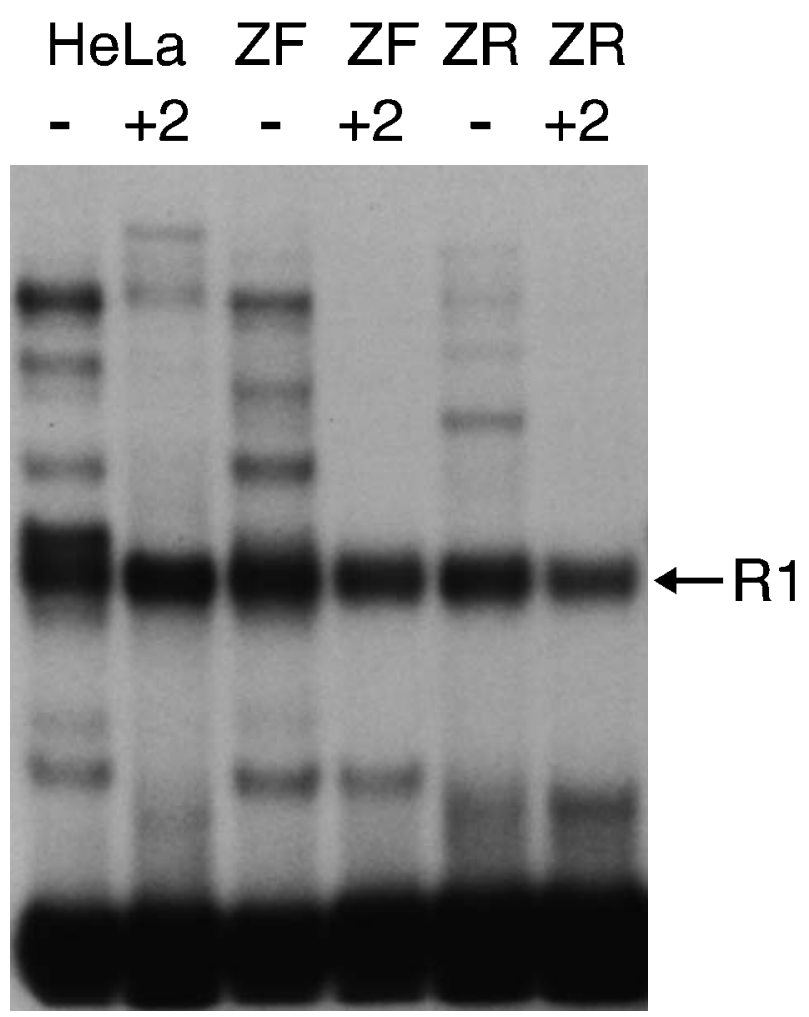

Figure 2 Formation of complex R1 in extracts from separated ZF and ZR cells. A labeled double-stranded oligonucleotide corresponding to an element in HSD3B1 (sequence 1 in Fig. 1) was incubated with nuclear extracts from adrenocortical cells (ZF or ZR) or from HeLa cells. +2 indicates that a 100-fold molar excess of an oligonucleotide based on HSD3B2 (sequence 2 in Fig. 1) was added during the binding reaction.

We performed gel-mobility shift analysis with competitor oligonucleotides to investigate the formation of the $\mathrm{C} 1$ complex with elements from HSD3B1 and HSD3B2. These studies were designed to characterize the region of the element required for $\mathrm{C} 1$ complex formation and to find out whether a shorter sequence would still efficiently form a C1 complex. This information was subsequently used in the design of an oligonucleotide affinity column used for purification of the protein. Figure 4 shows that, as expected, all complexes formed by the oligonucleotide based on HSD3B2 were disrupted in the presence of an excess of the same sequence. A similar result was obtained with an excess of an oligonucleotide based on HSD3B1 in which bases in the $5^{\prime}$ part of the sequence have been changed to those of HSD3B2 (sequence 1a in Fig. 1). Thus the ZF-specific protein forming $\mathrm{C} 1$ appears to bind both to HSD3B2 and HSD3B1, presumably to the $3^{\prime}$ part of the element where the two sequences are most similar. In the presence of the unmutated HSD3B1 sequence the C1 complex was disrupted, but two rapidly migrating complexes were formed (designated $\mathrm{C} 2 / \mathrm{C} 3$ ), concomitant with the disappearance of two slower-migrating 


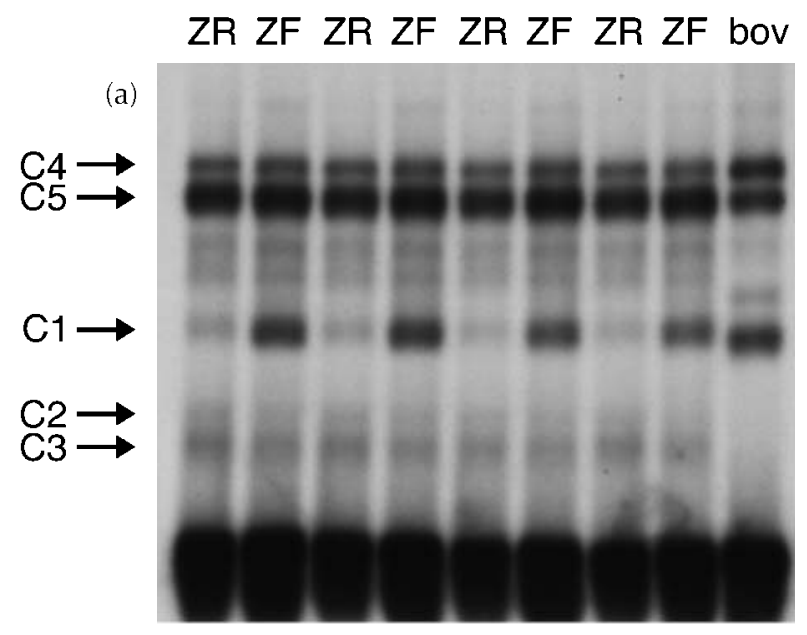

\section{ZR ZF ZR ZF ZR ZF ZR ZF 0}

(b)

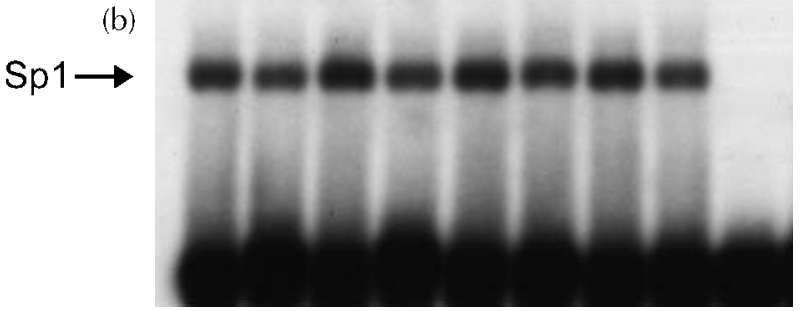

Figure 3 Complexes formed with a probe based on HSD3B2. In (a) nuclear extracts from four pairs of ZF and ZR cells were incubated with labeled oligonucleotide (sequence 2 in Fig. 1). Cells were obtained from four adrenal glands from donors of 36, 44, 53 and 60 years of age. Additionally nuclear extract from bovine adrenal cortex (bov) was used. The ZF-specific complex C1 is indicated. In (b) ZR and ZF cell extracts were incubated with a labeled oligonucleotide of a sequence that binds Sp1. 0 indicates the no-extract control. complexes (designated C4/C5). Because the $\mathrm{C} 2 / \mathrm{C} 3$ pair is not formed in the presence of sequence $1 \mathrm{a}$, but is formed in the presence of the unmutated sequence, the proteins involved appear to bind to the $5^{\prime}$ part of the HSD3B2 element. The C4/C5 pair is presumably formed when the $\mathrm{C} 1$ protein is also bound by the probe. This conclusion is consistent with results obtained when competition experiments were performed using ZR cell extract (Fig. 4). ZR cell extract formed a less-prominent $\mathrm{C} 4 / \mathrm{C} 5$ pair whereas the $\mathrm{C} 2 / \mathrm{C} 3$ pair was formed even without the HSD3B1 competitor. This indicates that the proteins forming $\mathrm{C} 2 / \mathrm{C} 3$ are found in both $\mathrm{ZR}$ and $\mathrm{ZF}$ cells.

These conclusions were confirmed by analysis of the effects of competitor oligonucleotides based on the $5^{\prime}$ part of the element, extending to the boundary of the $3 \beta \mathrm{I}-\mathrm{A}$ and GT box sub-elements, as previously defined by Guerin et al. (1995; Fig. 1). Oligonucleotides based on the 5' part of HSD3B2 (2c and 2d) disrupted the C4/C5 pair of complexes without disrupting C1 (Fig. 4). However sequence $2 \mathrm{~b}$, in which five bases have been mutated to those of HSD3B1, did not affect C4/C5. Sequence 2d differs from $2 \mathrm{~b}$ in that two bases only have been mutated. Taken together these findings indicate that formation of the C4/C5 complexes depends on an unmutated HSD3B2 sequence in bases beyond the $5^{\prime}$ end of the 3ßI-A sub-element (Fig. 1). None of the truncated oligonucleotides based on HSD3B1, even when bases were mutated to those of HSD3B2 (1b, 1c, 1d) disrupted the C4/C5 complexes. This indicates that the central pair of bases (CA) present in HSD3B1 does not permit binding of the proteins forming these complexes. The competition analysis also confirmed that the formation of complex $\mathrm{C} 1$ requires the $3^{\prime}$ end of $\mathrm{HSD} 3 \mathrm{~B} 1$ or $\mathrm{HSD} 3 \mathrm{~B} 2$. C1 was disrupted by sequences $1,1 \mathrm{a}, 2$ and $2 \mathrm{a}$. It was not disrupted by truncated oligonucleotides, except partially
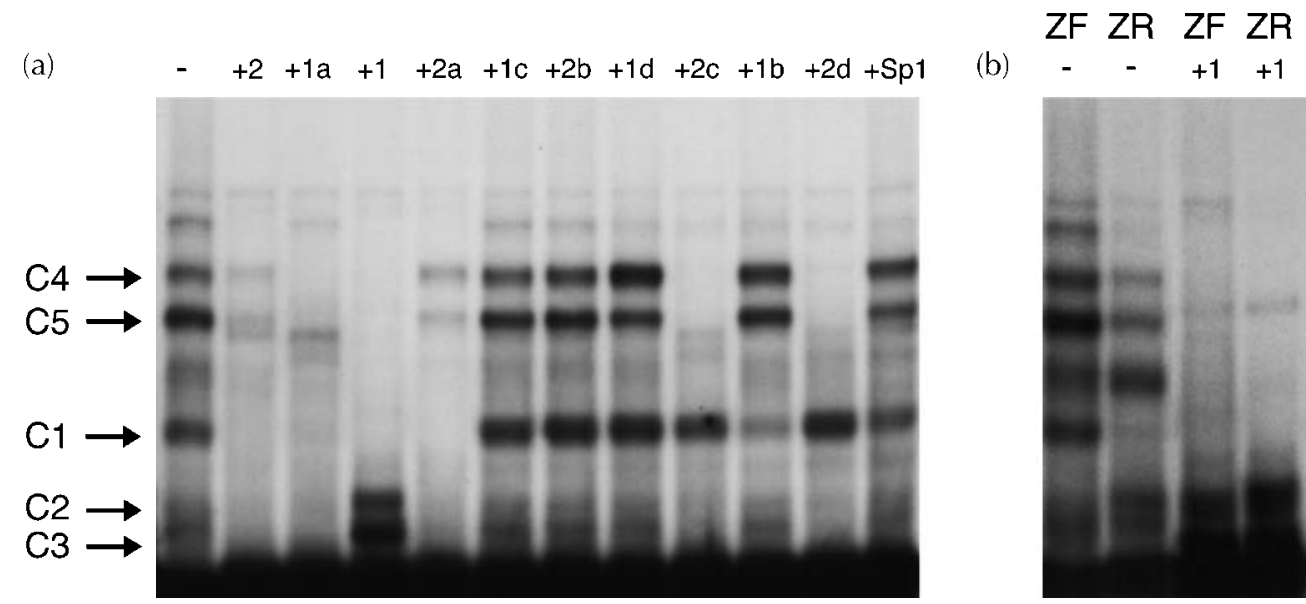

Figure 4 Gel-mobility shift competition analysis on nuclear extract proteins bound to HSD3B2. All reactions comprised nuclear extract proteins (all from human ZF cells except where indicated) and the labeled probe based on HSD3B2 (sequence 2 in Fig. 1). Competitor oligonucleotides were added at 100-fold molar excess in the binding reaction. The oligonucleotides used are indicated above the lanes; the sequences are shown in Fig. 1. Positions of complexes designated C1 to C5 are indicated (see text). 
by sequence $1 \mathrm{~b}$, which was based on HSD3B1 with five bases mutated to the sequence of HSD3B2. This indicates that although $\mathrm{C} 1$ formation requires the $3^{\prime}$ end of the sequence, formation of this complex is still affected by the context of the $5^{\prime}$ part of the sequence. Consistent with this conclusion, we found that shorter oligonucleotides, in which bases have been removed from the $5^{\prime}$ end of the HSD3B2 element, did not strongly bind proteins from adrenocortical cell extracts when used as labeled probes (results not shown).

We concluded that an oligonucleotide affinity column for purification of the ZF-specific nuclear protein forming the $\mathrm{C} 1$ complex would need to be formed from the full-length HSD3B2 element. Because such an oligonucleotide would bind more than one protein, some fractionation of the nuclear extract would be required before affinity-column purification. We investigated whether chromatography on DEAE and carboxymethyl ion-exchange columns would be useful for separation of the $\mathrm{C} 1$ complex protein. Human adrenocortical nuclear extract was applied to a DEAE ion-exchange column and proteins were eluted with $40 \mathrm{mM} \mathrm{KCl} \mathrm{(Fig.} \mathrm{5).} \mathrm{Fractions}$ were assayed by gel-mobility shift using the probe based on HSD3B2. The protein forming the C1 complex eluted rapidly from the column. Other proteins that bind to HSD3B2, producing slower-migrating complexes from unfractionated extract, eluted later. The early fractions therefore comprise a partially purified preparation of a protein forming the $\mathrm{C} 1$ complex. Further elution with 70 and $100 \mathrm{mM} \mathrm{KCl}$ buffers did not yield fractions with more $\mathrm{C} 1$ complex. Figure 5 also shows that a protein producing a similar gel-shift pattern also eluted rapidly with $40 \mathrm{mM}$ $\mathrm{KCl}$ when bovine adrenocortical nuclear extract was fractionated. Moreover the same pattern was observed when we tested nuclear extracts from a variety of human cell lines (results not shown). C1 complex protein also eluted rapidly from a carboxymethyl ion-exchange column (results not shown).

Competition assays performed with partially purified C1 complex protein gave results that were consistent with those obtained with crude extracts. The complex was disrupted by those oligonucleotides that disrupt the $\mathrm{C} 1$ complex formed from the unfractionated extract (Fig. 6). It was partially disrupted by $1 \mathrm{~b}$ and fully disrupted by the unmutated HSD3B2 element. It was not disrupted by unrelated competitor oligonucleotides comprising binding sequences for SF-1 and Sp1 (Fig. 6, and data not shown).

Based on these analyses we sought to purify and identify the protein forming the $\mathrm{C} 1$ complex. An oligonucleotide affinity column was constructed using double-stranded DNA based on the sequence of the HSD3B2 element. Covalently attached biotin was used to attach the DNA to strepavidin-modified beads. Because of the limited supply of human adrenocortical tissue, and because we observed that a $\mathrm{C} 1$ complex was formed by extracts derived from a variety of human cells, we used a human cell line
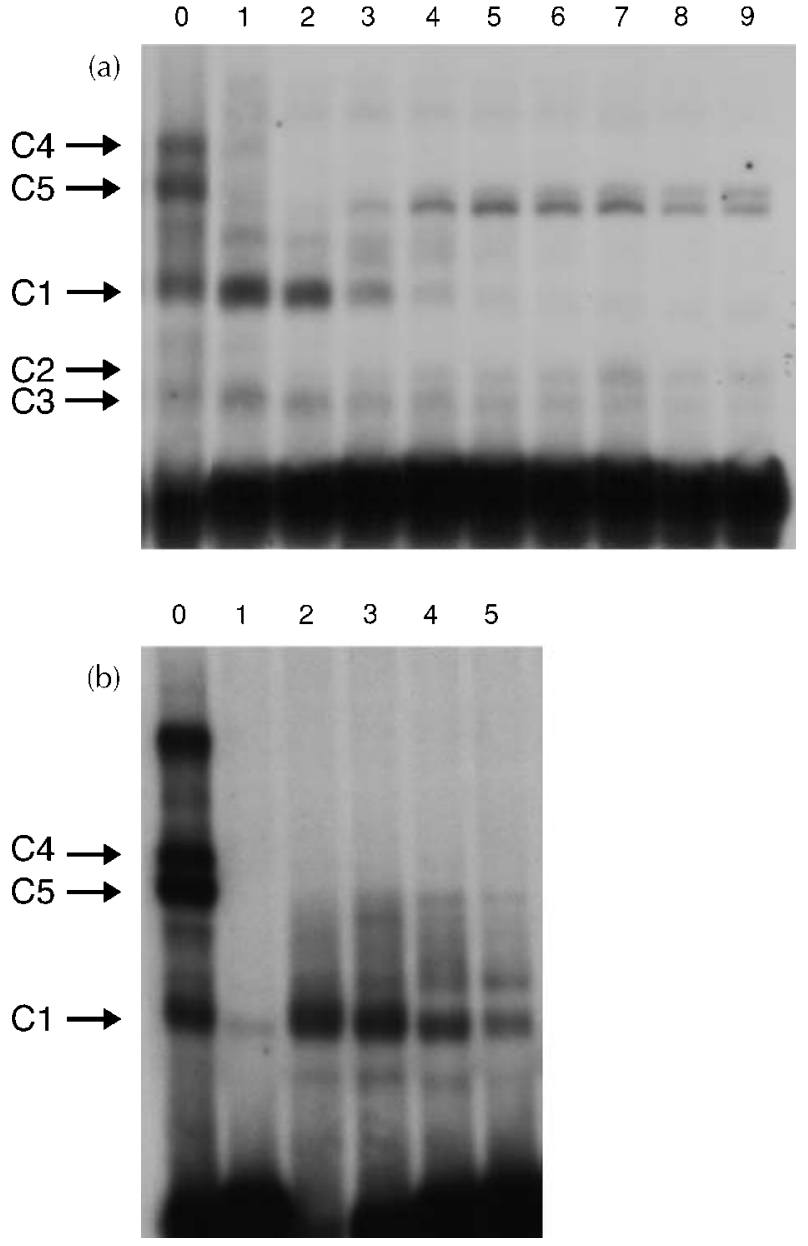

Figure 5 Gel-mobility shift analysis of fractionated proteins from human (a) and bovine (b) adrenal cortex. Unfractionated nuclear extract incubated with labeled HSD3B2 probe was used in lane 0. In lanes 1-9 (human) or 1-5 (bovine) fractions eluted from a DEAE ion-exchange column were incubated with labeled probe (see the Materials and Methods section).

(IMR-32) as a source of nuclear extract proteins. To remove other proteins that bind to the HSD3B2 element the extract was passed through DEAE and carboxymethyl columns and the early-eluting proteins were applied to the oligonucleotide affinity column. The oligonucleotideprotein complex was eluted with biotin and adsorbed on to PVDF membrane. The adsorbed protein was subjected to mass spectrometry analysis. The only significant hit (probability-based MOWSE score of 94) was $\alpha$-enolase. Scores $>56$ indicate that the observed match is significant, i.e. that the probability of a random match is $<0 \cdot 05$.

$\alpha$-Enolase is a multifunctional protein that has been shown to bind to DNA. Although the entire protein can bind (Feo et al. 2000, Subramanian and Miller 2000), binding also resides in an $\mathrm{N}$-terminal-truncated form of $\alpha$-enolase that arises by use of an internal translational start site. 

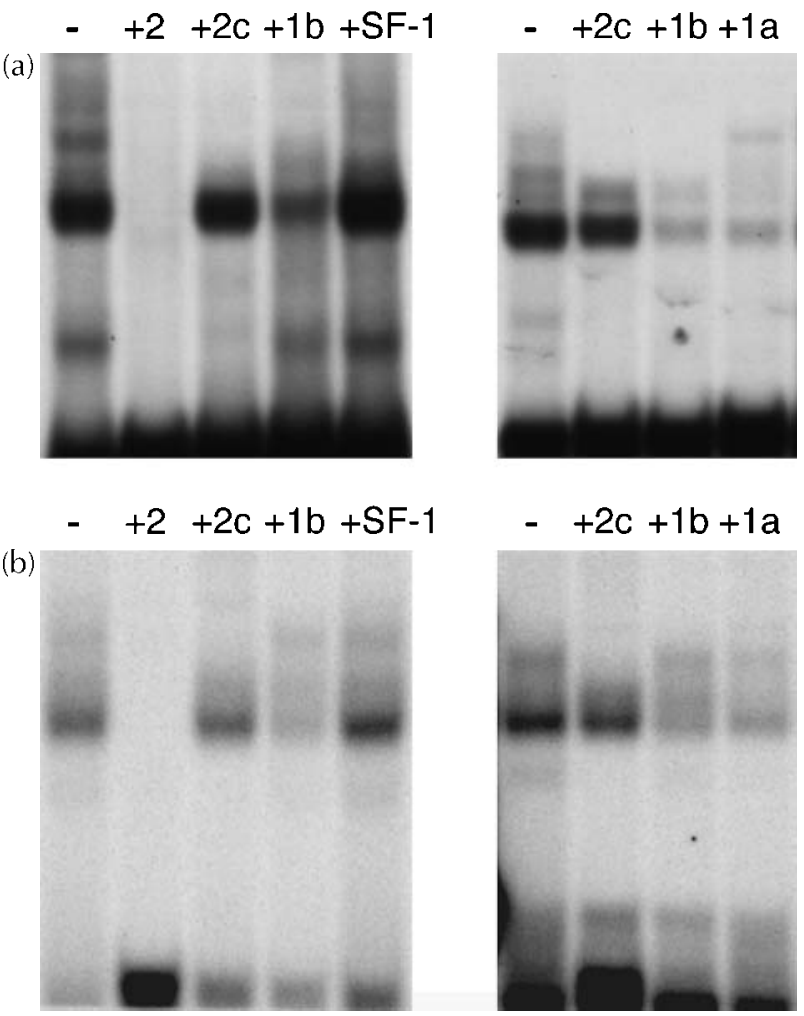

(b)

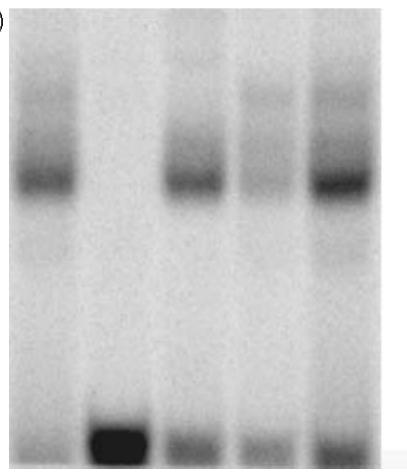

Figure 6 Gel-mobility shift competition analysis of partially purified C1 complex protein from human (a) and bovine (b) nuclear extracts. Two different preparations from each source were used. Each binding reaction contained HSD3B2 probe with $5 \mu \mathrm{g}$ protein pooled from fractions 1 and 2 (human) or 2-4 (bovine) (see Fig. 5). Competitor oligonucleotides as indicated above the lanes were added at 100 -fold molar excess.

This protein, termed $\mathrm{c}-m y c$ promoter-binding protein (MBP-1), binds to a region around the major (P2) promoter of the c-myc gene (Ray and Miller 1991). We tested whether the C1 complex was disrupted by a double-stranded oligonucleotide that was initially characterized for binding of MBP-1 (Ray and Miller 1991) and which was subsequently used in binding the full $\alpha$-enolase protein (Feo et al. 2000, Subramanian and Miller 2000). Figure 7 shows that the MBP-1 oligonucleotide does in fact disrupt the C1 complex. As controls we tested double-stranded oligonucleotides based on the binding sites for eight other DNA-binding proteins; none of these oligonucleotides disrupted the C1 complex at a 100-fold molar ratio, indicating the specificity of disruption by the MBP-1 oligonucleotide (results not shown).

The competitive gel-shift and protein-purification experiments lead to the conclusion that $\alpha$-enolase is a protein with a nuclear localization in ZF cells but not in ZR cells. In order to study this further, the subcellular localization of $\alpha$-enolase was examined by immunohistochemistry. In sections of adrenal cortex from several different donors we

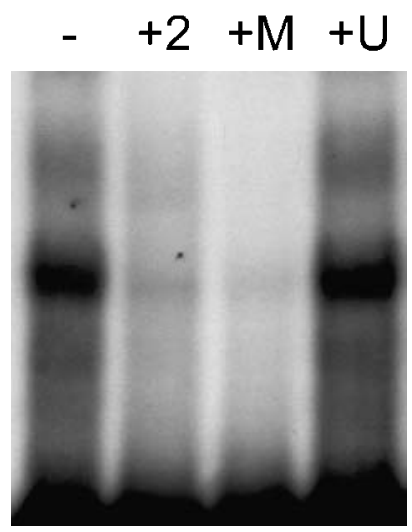

Figure 7 Competition for $\mathrm{C} 1$ complex with an oligonucleotide that binds $\alpha$-enolase and its alternate translational form MBP-1. Bovine adrenal nuclear extract that had been passed over DEAE- and carboxymethyl-Sepharose columns, as described in the text, was incubated with labeled HSD3B2 probe (-). In the other lanes 100-fold molar excess of competitor oligonucleotides were added: the HSD3B2 element $(+2)$, the c-myc P2 promoter $(+M)$ and an unrelated sequence $(+U)$.

found that $\alpha$-enolase staining was nuclear in the $\mathrm{ZF}$ and cytoplasmic in the ZR (Fig. 8). In ZF cells staining was almost entirely nuclear with little cytoplasmic staining. In $\mathrm{ZR}$ cells staining in many cells was confined to the cytoplasm and the nucleus was negative; in others staining appeared to be both cytoplasmic and nuclear. This could be caused by cellular heterogeneity or alternatively it could result from some overlap of cytoplasm and nucleus in the section.

These experiments establish that $\alpha$-enolase is a DNAbinding protein with a zone-specific subcellular location in the human adrenal cortex, but leave open the question of whether $\alpha$-enolase affects the activity of the HSD3B2 promoter. To address this question we assessed the effects of $\alpha$-enolase on HSD3B2 promoter activity in cotransfection experiments (Fig. 9). These studies used the functional human adrenocortical cell line NCI-H295R (Rainey et al. 1994). Increasing amounts of an $\alpha$-enolase expression plasmid increased HSD3B2 promoter activity, but only when the construct contained the first intron $(-1019 /+203)$. The shorter construct $(-1019 /+13)$ was unaffected by co-transfected $\alpha$-enolase. In separate experiments the increase in promoter activity induced by $\alpha$-enolase was variable but statistically significant. Possible causes of the variability are discussed below.

\section{Discussion}

An adrenocortical DNA-binding protein was identified as $\alpha$-enolase and was shown to have a nuclear localization in human ZF cells, whereas it was predominantly 

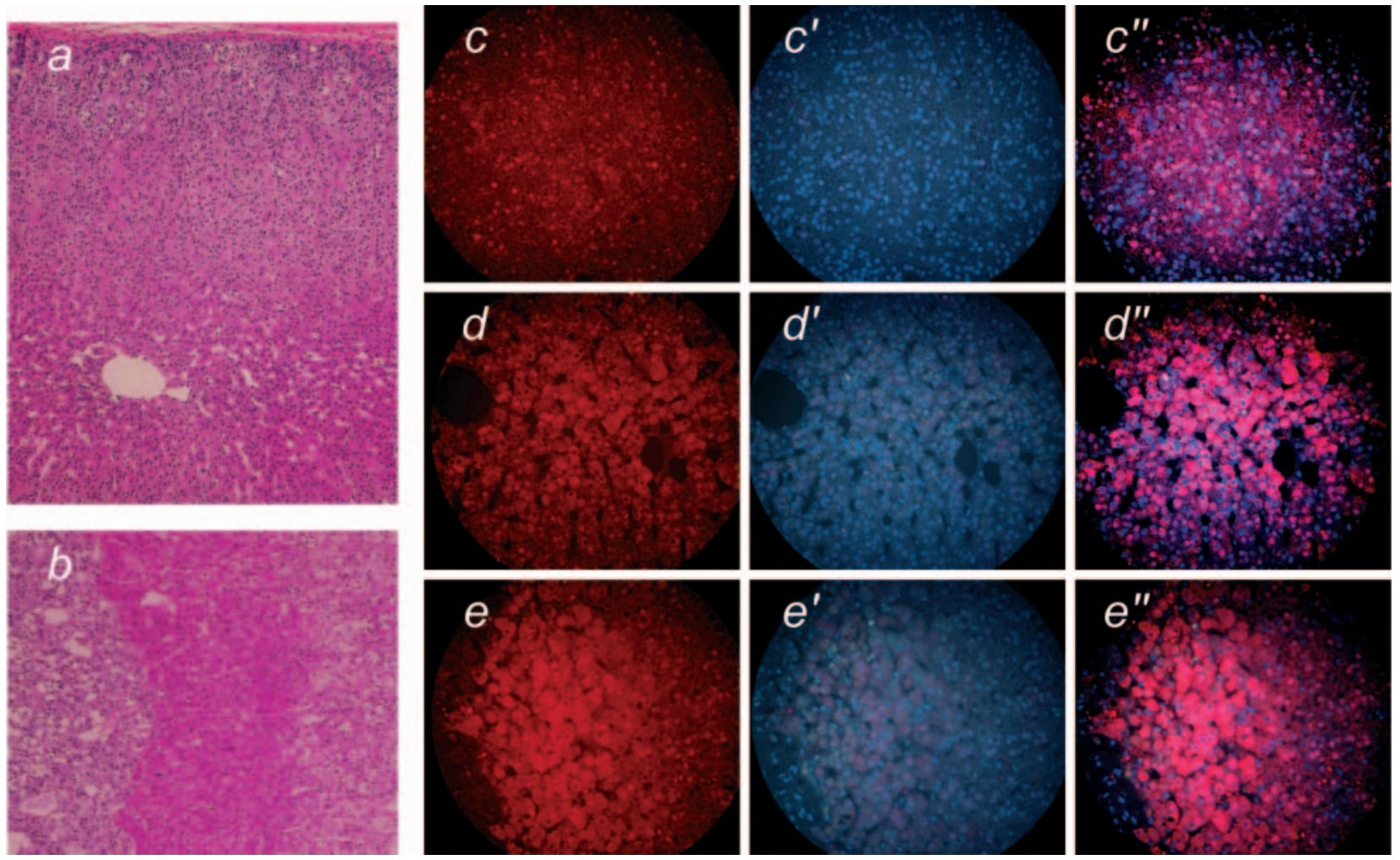

Figure 8 Immunocytochemical investigation of the distribution of $\alpha$-enolase in the human adrenal cortex. (a, b) Hematoxylin- and eosin-stained sections of the adrenal cortex from different donors. The section in (a) shows a part of the gland where two opposing layers of cortex meet at the the alar raphe (Dobbie and Symington 1966) and no medulla is present. The section in (b) shows medulla on the left, ZR in the center and ZF on the right. The fluorescence images in (c) and (d) are from sections adjacent to that shown in (a) and the images in (e) are from a section adjacent to that shown in (b). (c) is located in the middle of the ZF; (d) centers on the two facing ZR layers on either side of the alar raphe, and includes some ZF cells at both the top and bottom of the image; (e) centers on the ZR, with medulla on the left and part of the ZF on the right. Sections were incubated with $\alpha$-enolase antibody, which was visualized with a red quantum dot conjugate. Sections were counterstained with DAPI (blue; $\left.c^{\prime}-e^{\prime}\right)$ to show the nuclei. In $\left(c^{\prime \prime}\right)$, $\left(d^{\prime \prime}\right)$ and $\left(e^{\prime \prime}\right)$ the red and blue images have been merged.

cytoplasmic in ZR cells. $\alpha$-Enolase is a multifunctional protein, having several distinct molecular activities. Apart from its role in glycolysis, it is a surface receptor for the binding of plasminogen, a lens crystallin, a hypoxic stress protein and an autoimmune antigen (Pancholi 2001). As a protein involved in glycolysis it is expected to be cytoplasmic, but it is found in the nucleus in several cell types. Western blotting shows it to be present in both nucleus and cytoplasm of endothelial cells (Aaronson et al. 1995) and HeLa cells (Subramanian and Miller 2000). Immunohistochemistry shows a nuclear location for $\alpha$-enolase in astrocytes (Langley and Ghandour 1981), type II neurons of the spiral ganglia (Dechesne and Keller 1996), bronchial epithelial cells, type I and type II alveolar cells and endothelial cells (Chang et al. 2003). During muscle regeneration $\alpha$-enolase changes from a cytoplasmic to a perinuclear location (Merkulova et al. 2000). Proteomic studies have shown $\alpha$-enolase to be found in the nuclei of Burkitt lymphoma BL 60 cells (Muller et al. 1999) and HEK-293 kidney cells (Schirle et al. 2003).
$\alpha$-Enolase and its alternate translational form MBP-1 bind and negatively regulate the major (P2) promoter of the c-myc gene (Feo et al. 2000, Subramanian and Miller 2000, Ray and Miller 1991). These proteins bind in the minor groove surface of the TATA-box motif of DNA together with TATA-box-binding protein (TBP; Chaudhary and Miller 1995). Although both $\alpha$-enolase/ MBP-1 and TBP bind to the TATA box, $\alpha$-enolase/ MBP-1 does not bind to all promoters, and the precise sequence requirements for binding other than the TATA box element are not established. A plant $\alpha$-enolase was shown to bind to a TATA-like element in the ZAT10 gene (Lee et al. 2002). Figure 10 compares the $\alpha$-enolase-binding sequences of the c-myc promoter, the element in the ZAT10 gene, and the element used here from the first intron of HSD3B2. The central sequence in the HSD3B2 element, TAAAAAA, is a TBP-binding element but does not act as a promoter (Bernues et al. 1996, Patikoglou et al. 1999, Mishra et al. 2003). 


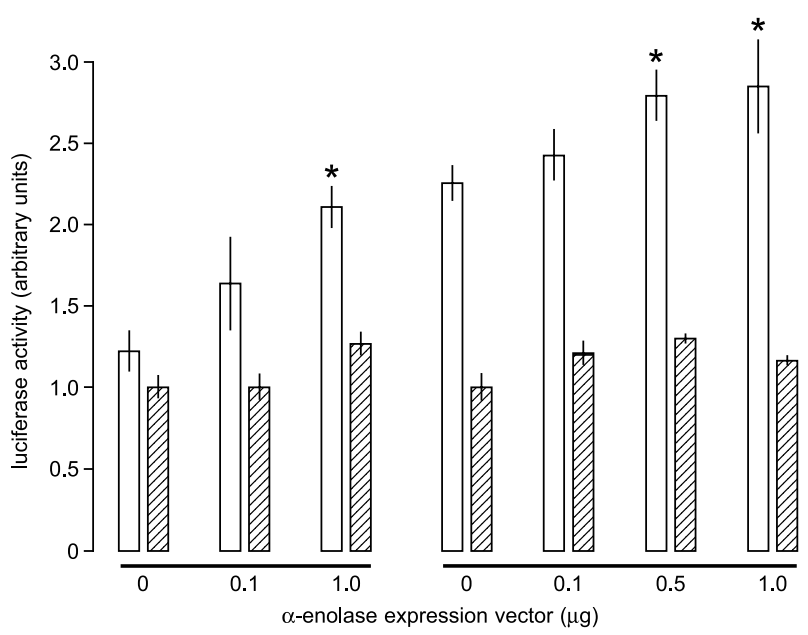

Figure 9 Effect of $\alpha$-enolase on HSD3B2 promoter activity. $\mathrm{NCl}-295 \mathrm{R}$ cells were transfected with luciferase reporter constructs containing either nucleotides $-1019 /+203$ of the human HSD3B2 gene (open bars) or $-1019 /+13$ (striped bars). Firefly luciferase activity was normalized to an internal control (Renilla luciferase plasmid). Two separate experiments are shown here. The amounts $(\mu \mathrm{g})$ of co-transfected $\alpha$-enolase expression vector are indicated. Each bar shows the mean \pm S.E. for normalized luciferase activity from four wells. Asterisks indicate values significantly different $(P<0 \cdot 05)$ from the corresponding cells not transfected with $\alpha$-enolase.

The impetus for examining proteins binding to the HSD3B2 gene was to find transcription factors that could be involved in the differential regulation of this gene in the zones of the adrenal cortex. The discovery of $\alpha$-enolase as a DNA-binding protein in the nuclei of ZF cells raises the question of whether $\alpha$-enolase could be involved in the regulation of $3 \beta-\mathrm{HSD}$. In co-transfection experiments an $\alpha$-enolase expression vector increased the activity of the HSD3B2 promoter, but only when the promoter contained the first intron of the gene, i.e. only when the $\alpha$-enolase-binding site was present. The degree of stimulation of promoter activity by $\alpha$-enolase was variable but statistically significant. Although the cause of the variability is unknown, it may result from the presence of endogenous $\alpha$-enolase in the adrenocortical cell line used.

\section{GTAAAAAATGGGGT HSD3B2 GTATAAAAGCCGGT c-myc \\ ATATAAAATCCGTA ZAT10}

Figure 10 Comparison of the $\alpha$-enolase-binding elements in HSD3B2, c-myc (Ray and Miller 1991) and ZAT10 ( -763 to -748 in the ZAT10 gene; Lee et al. 2002). Nucleotides in c-myc and ZAT10 that are common to HSD3B2 are shown with a gray background.
Levels could vary due to the growth status or other properties of the cells; this could blunt the effects of overexpression of the protein. It is also possible that $\alpha$-enolase may play a role in the regulation of c-myc expression in the adrenal cortex; it is of interest that c-myc was previously identified as a gene with higher expression in ZR cells (Wang et al. 2001). The significance of the present experiments is that they add to a growing appreciation that the ZR cell is a molecularly distinct cell type within the human adrenal cortex, despite the fact that the biological significance of its major product, DHEA(S), remains largely unknown (Hornsby 1995).

\section{Funding}

This work was supported by a grant from the National Institute on Aging (AG 12287). The authors declare that there is no conflict of interest that would prejudice the impartiality of this scientific work.

\section{References}

Aaronson RM, Graven KK, Tucci M, McDonald RJ \& Farber HW 1995 Non-neuronal enolase is an endothelial hypoxic stress protein. Journal of Biological Chemistry 270 27752-27757.

An MR, Hsieh CC, Reisner PD, Rabek JP, Scott SG, Kuninger DT \& Papaconstantinou J 1996 Evidence for posttranscriptional regulation of $\mathrm{C} / \mathrm{EBP} \alpha$ and $\mathrm{C} / \mathrm{EBP} \beta$ isoform expression during the lipopolysaccharide-mediated acute-phase response. Molecular Cellular Biology 16 2295-2306.

Bernues J, Carrera P \& Azorin F 1996 TBP binds the transcriptionally inactive TA5 sequence but the resulting complex is not efficiently recognised by TFIIB and TFIIA. Nucleic Acids Research $\mathbf{2 4}$ 2950-2958.

Chang YS, Wu W, Walsh G, Hong WK \& Mao L 2003 Enolase- $\alpha$ is frequently down-regulated in non-small cell lung cancer and predicts aggressive biological behavior. Clinical Cancer Research 9 3641-3644.

Chaudhary D \& Miller DM 1995 The c-myc promoter binding protein (MBP-1) and TBP bind simultaneously in the minor groove of the c-myc P2 promoter. Biochemistry 34 3438-3445.

Dechesne CJ \& Keller A 1996 Differential $\alpha$ enolase immunoreactivity in the two neuron types of the rat spiral ganglion during postnatal development. Comparison with neurofilament protein immunoreactivity. Auditory Neuroscience 2 33-46.

Dobbie JW \& Symington T 1966 The human adrenal gland with special reference to the vasculature. Journal of Endocrinology 34 479-489.

Endoh A, Kristiansen SB, Casson PR, Buster JE \& Hornsby PJ 1996 The zona reticularis is the site of biosynthesis of dehydroepiandrosterone and dehydroepiandrosterone sulfate in the adult human adrenal cortex resulting from its low expression of $3 \beta$-hydroxysteroid dehydrogenase. Journal of Clinicial Endocrinology and Metabolism 81 3558-3565.

Feo S, Arcuri D, Piddini E, Passantino R \& Giallongo A 2000 ENO1 gene product binds to the $\mathrm{c}$-myc promoter and acts as a transcriptional repressor: relationship with Myc promoter binding protein 1 (MBP-1). FEBS Letters 473 47-52.

Gell JS, Carr BR, Sasano H, Atkins B, Margraf L, Mason JI \& Rainey WE 1998 Adrenarche results from development of a 
$3 \beta$-hydroxysteroid dehydrogenase-deficient adrenal reticularis. Journal of Clinical Endocrinology and Metabolism 83 3695-3701.

Guerin SL, Leclerc S, Verreault H, Labrie F \& Luu-The V 1995 Overlapping cis-acting elements located in the first intron of the gene for type I $3 \beta$-hydroxysteroid dehydrogenase modulate its transcriptional activity. Molecular Endocrinology 9 1583-1597.

Hornsby PJ 1995 Biosynthesis of DHEAS by the human adrenal cortex and its age related decline. Annals of the New York Academy of Sciences 774 29-46.

Hornsby PJ \& McAllister JM 1991 Culturing steroidogenic cells. Methods in Enzymology 206 371-380.

Jimenez P, Saner K, Mayhew B \& Rainey WE 2003 GATA-6 is expressed in the human adrenal and regulates transcription of genes required for adrenal androgen biosynthesis. Endocrinology 144 $4285-4288$.

Kennerson AR, McDonald DA \& Adams JB 1983 Dehydroepiandrosterone sulfotransferase localization in human adrenal glands: a light and electron microscopic study. Journal of Clinical Endocrinology and Metabolism 56 786-790.

Lachance Y, Luu-The V, Verreault H, Dumont M, Rheaume E, Leblanc G \& Labrie F 1991 Structure of the human type II $3 \beta$-hydroxysteroid dehydrogenase $/ \Delta^{5}-\Delta^{4}$ isomerase $(3 \beta-H S D)$ gene: Adrenal and gonadal specificity. DNA and Cell Biology 10 701-711.

Langley OK \& Ghandour MS 1981 An immunocytochemical investigation of non neuronal enolase in cerebellum: a new astrocyte marker. Histochemical Journal 13 137-148.

Lee H, Guo Y, Ohta M, Xiong L, Stevenson B \& Zhu JK 2002 LOS2, a genetic locus required for cold-responsive gene transcription encodes a bi-functional enolase. EMBO Journal 21 2692-2702.

Marx C, Bornstein SR, Wolkersdorfer GW, Peter M, Sippell WG \& Scherbaum WA 1997 Relevance of major histocompatibility complex class II expression as a hallmark for the cellular differentiation in the human adrenal cortex. Journal of Clinical Endocrinology and Metabolism 82 3136-3140.

Merkulova T, Dehaupas M, Nevers MC, Creminon C, Alameddine H \& Keller A 2000 Differential modulation of $\alpha, \beta$ and $\gamma$ enolase isoforms in regenerating mouse skeletal muscle. European Journal of Biochemistry 267 3735-3743.

Mishra AK, Vasanthi P \& Bhargava P 2003 The transcriptional activator GAL4-VP16 regulates the intra-molecular interactions of the TATA-binding protein. Journal of Bioscience 28 423-436.

Muller EC, Schumann M, Rickers A, Bommert K, Wittmann-Liebold B \& Otto A 1999 Study of Burkitt lymphoma cell line proteins by high resolution two-dimensional gel electrophoresis and nanoelectrospray mass spectrometry. Electrophoresis 20 320-330.
Pancholi V 2001 Multifunctional $\alpha$-enolase: its role in diseases. Cellular Molecular Life Sciences 58 902-920.

Parker CR Jr 1997 Normal regulation of adrenal androgen production. In Androgen Excess Disorders in Women, pp 23-35. Eds R Azziz, JE Nestler \& D Dewailly. Philadelphia: Lippincott-Raven Publishers.

Patikoglou GA, Kim JL, Sun L, Yang SH, Kodadek T \& Burley SK 1999 TATA element recognition by the TATA box-binding protein has been conserved throughout evolution. Genes $\mathcal{E}$ Development 13 3217-3230.

Rainey WE, Bird IM \& Mason JI 1994 The NCI-H295 cell line: A pluripotent model for human adrenocortical studies. Molecular and Cellular Endocrinology 100 45-50.

Ray R \& Miller DM 1991 Cloning and characterization of a human c-myc promoter-binding protein. Molecular Cellular Biology 11 2154-2161.

Sasano H, Mason JI, Sasano N \& Nagura H 1990 Immunolocalization of $3 \beta$-hydroxysteroid dehydrogenase in human adrenal cortex and its disorders. Endocrine Pathology 1 94-101.

Schirle M, Heurtier MA \& Kuster B 2003 Profiling core proteomes of human cell lines by one-dimensional PAGE and liquid chromatography-tandem mass spectrometry. Molecular and Cellular Proteomics 2 1297-1305.

Sirianni R, Carr BR, Ando S \& Rainey WE 2003 Inhibition of Src tyrosine kinase stimulates adrenal androgen production. Journal of Molecular Endocrinology 30 287-299.

Subramanian A \& Miller DM 2000 Structural analysis of $\alpha$-enolase. Mapping the functional domains involved in down-regulation of the c-myc protooncogene. Journal of Biological Chemistry 275 5958-5965.

Thomas MJ, Gronowski AM, Berry SA, Bergad PL \& Rotwein P 1995 Growth hormone rapidly activates rat serine protease inhibitor $2 \cdot 1$ gene transcription and induces a DNA-binding activity distinct from those of Stat1, -3, and -4. Molecular Cellular Biology 15 12-18.

Vostrov AA \& Quitschke WW 1997 The zinc finger protein CTCF binds to the APB $\beta$ domain of the amyloid $\beta$-protein precursor promoter. Evidence for a role in transcriptional activation. Journal of Biological Chemistry 272 33353-33359.

Wang W \& Klein WH 1996 A G/C-rich DNA-regulatory element controls positive expression of the sea urchin Lytechinus pictus aboral ectoderm-specific LpS1 gene. DNA and Cell Biology 15 133-145.

Wang W, Yang L, Suwa T, Casson PR \& Hornsby PJ 2001 Differentially expressed genes in zona reticularis cells of the human adrenal cortex. Molecular and Cellular Endocrinology 173 127-134.

Received 21 September 2004

Accepted 30 September 2004 